http://dx.doi.org/10.18232/alhe.1117

Artículos

\title{
Los legados de la guerra de independencia y la revolución sobre la violencia criminal en México
}

\section{The Legacies of Independence War and Revolution on Criminal Violence in Mexico}

\author{
Luz Marina Arias 1, * (D) 0000-0002-8180-8962 \\ Luis Miguel de la Calle Robles ${ }^{1}$ (D) 0000-0003-2099-4746 \\ ${ }^{1}$ Centro de Investigación y Docencia Económicas, Ciudad de México, México. \\ *Correspondencia: luz.arias@cide.edu
}

Resumen. Este trabajo se enfoca en las conexiones históricas de la violencia criminal contemporánea en México. Investiga si la guerra de independencia y la revolución muestran alguna línea de continuidad con la actual oleada de violencia criminal. Encontramos que la violencia criminal se concentra principalmente en municipios que tuvieron presencia rebelde durante el periodo revolucionario. Además, los municipios en los que se crearon milicias realistas durante la guerra de independencia muestran una menor violencia criminal hoy en día. El legado de la violencia parece transitar a través de dos caminos causales. Los municipios hoy más violentos son aquellos que contaban con una menor presencia de instituciones indígenas durante el virreinato (los llamados pueblos de indios). Además, los municipios con más capacidades estatales locales a finales del siglo XIX tienen menos violencia hoy. Por el contrario, las varias reformas de la tierra del periodo autoritario no parecen reducir la violencia criminal.

Palabras clave: violencia; guerras civiles; independencia de México; revolución mexicana; criminalidad.

CÓMO CITAR: Arias, L. M. y De la Calle, L. M. (2021). Los legados de la guerra de Independencia y la revolución sobre la violencia criminal en México. América Latina en la Historia Económica, 28(2), 1-26. DOI: 10.18232/alhe.1117 
Abstract. This paper offers a novel approach to the study of criminal violence in Mexico by focusing on its historical connections with the War of Independence and the Revolution. We find that criminal violence is mainly concentrated in municipalities that had a rebel presence during the Mexican Revolution. In turn, the municipalities where royalist militias were created during the War of Independence show less criminal violence today. This legacy of violence appears to travel through two causal paths. Firstly, the most violent municipalities today are those that had on average a lower presence of indigenous institutions during the viceroyalty (the so-called pueblos de indios). Second, municipalities with a higher local state capacity in the late 19th century are better at containing contemporary criminal violence. In contrast, the various land reforms of the authoritarian period do not appear to have a systematic effect on reducing criminal violence.

Key words: violence; civil wars; Mexican Independence; Mexican Revolution; criminality.

JEL: H39; N46; N96.

Recibido: 26 de septiembre de 2019.

Aceptado: 10 de noviembre de 2020.

Publicado: 30 de abril de 2021.

\section{INTRODUCGIÓN}

La violencia criminal es uno de los principales problemas contemporáneos de México. Las disputas entre bandas criminales por el control de las rutas de trasiego de drogas hacia Estados Unidos, así como por el monopolio de la extracción de rentas de los ciudadanos, han producido más de 100000 muertos desde que el país transitó hacia la democracia a principios del siglo xxi (Schedler, 2015). Numerosas investigaciones se han centrado en analizar las causas contemporáneas del espectacular crecimiento de la criminalidad en México; en cambio, este trabajo ofrece una aproximación original de largo aliento para observar las similitudes históricas entre la violencia actual y las dos principales oleadas de violencia política que ha sufrido el país -la guerra de independencia y la revolución.

No dudamos que la violencia criminal persigue objetivos muy distintos a los que se buscaron en esos dos grandes conflictos del pasado, ya que se rige por una encarnizada rivalidad entre grupos que controlan el comercio de mercancías ilegales y la extracción de rentas de las poblaciones locales, con el fin de monopolizar mercados y evitar la competencia. Pero también, muestra una segunda dimensión de violencia contra instituciones y funcionarios públicos que empareja las motivaciones económicas con claras consecuencias políticas (De la Calle y Schedler, 2021). Por su parte, tanto la guerra de independencia como la revolución fueron conflictos con una clara raíz política, en la que también experimentaron explotación de recursos económicos y extracción de impuestos (Aboites y Jáuregui 2005).

Si hacemos abstracción de esas diferentes motivaciones, ¿es la violencia actual una simple continuación de las violencias del pasado, de forma que los municipios más afectados por la criminalidad son aquellos que experimentaron también los episodios previos de disrupción, o no hay ninguna relación entre estos eventos? De igual forma, es posible imaginarse un impacto más matizado de los conflictos pasados, de forma que independencia y revolución muestren una relación distinta con la violencia criminal actual. 
En este trabajo, investigamos a profundidad si las dos grandes explosiones de violencia civil que han afectado al país desde su fundación en el siglo xIx muestran alguna línea de continuidad con la actual oleada de violencia criminal. Por razones teóricas que discutimos en la siguiente sección, cruzamos el efecto de la guerra de independencia y el de la revolución para capturar mejor el impacto de los legados a partir de cuatro categorías substantivamente diferentes: $a$ ) aquellos municipios que no tuvieron presencia rebelde durante la revolución pero sí milicias realistas durante la independencia; $b$ ) municipios sin revolución y sin presencia realista; $c$ ) municipios con presencia rebelde durante la revolución pero sin presencia realista durante la independencia; y finalmente, $d$ ) municipios con revolución y realistas. Esta codificación nos permite identificar efectos divergentes de los legados de la violencia.

En segundo lugar, presentamos posibles mecanismos para analizar esas distintas dinámicas del impacto de la violencia en el tiempo. En tanto que la violencia política debilita la capacidad de los gobiernos locales para recaudar impuestos y proveer bienes públicos, los municipios con legados de violencia política deberían mostrar una menor capacidad para defenderse ante violencia futura, reforzando así la tendencia destructiva de la violencia sobre las posibilidades de construcción estatal. En la misma línea, instituciones que hayan servido a las comunidades para blindarlas ante amenazas externas en el pasado, podrían seguir operando como freno frente a la violencia criminal actual, incluso si dichas instituciones desaparecieron, como es el caso de los pueblos de indios creados durante el periodo colonial y extinguidos durante el siglo xIX, pero cuya presencia se mantiene a través de instituciones de gobernanza indígena.

Por otro lado, la violencia podría haber contribuido a dejar un legado de instituciones locales más fuertes. La creación de milicias realistas durante la guerra de independencia apunta a esta lógica, pues estos grupos armados extrajeron más impuestos para sufragar la guerra y, de paso, fortalecieron la capacidad de organización colectiva local -sobre todo, al unificar los esfuerzos de las elites locales para seguir controlando el poder municipal tras la consumación pactada de la independencia. Los municipios con esa herencia de mayor capacidad institucional -debido a la presencia original de milicias realistas- que evitaron la presencia rebelde durante la revolución, posiblemente son capaces de reducir el impacto de la actual violencia criminal.

Nuestros resultados apuntan a que, tanto la guerra de independencia como la revolución tienen un peso significativo sobre la violencia criminal de forma contrapuesta. Por un lado, los municipios que experimentaron movimientos revolucionarios tienen más violencia criminal que los municipios sin revolución y sin milicias realistas; por otro, los municipios con milicias realistas están mejor que los municipios sin revolución, y aquellos con revolución y realistas están ligeramente mejor que los municipios con revolución y sin realistas. Para desentrañar estos efectos, analizamos tres posibles mecanismos: la existencia de instituciones indígenas en localidades con menos violencia, el desarrollo de instituciones más fuertes en municipios con milicias realistas y finalmente, el fracaso de la reforma de la tierra durante el periodo autoritario como instrumento para pacificar las zonas que más experimentaron la violencia revolucionaria. Encontramos evidencia satisfactoria para los dos primeros, no tanto para el tercero. Todos estos resultados son robustos a la inclusión de factores contemporáneos identificados en la literatura y a diversas especificaciones econométricas.

En resumen, nuestros hallazgos muestran un claro legado del pasado cuyas conexiones con la violencia presente necesitan ser estudiadas con más detenimiento. Particularmente, el efecto de la revolución apunta a una herencia de violencia irresuelta por la reforma agraria que buscó aplacar las demandas locales y alimentó las revueltas en amplias partes del país. Por su parte, los municipios 
con milicias realistas fueron capaces de mejorar su fortaleza institucional para finales del siglo XIX y los que no sucumbieron a la violencia revolucionaria, han permanecido mejor equipados para reducir el impacto de la criminalidad.

En este artículo, primero discutimos la literatura enfocada en los factores contemporáneos explicativos de la violencia criminal; después, presentamos nuestros argumentos sobre la herencia de la violencia del pasado; a continuación, discutimos la evidencia cuantitativa; y cerramos con algunas reflexiones sobre cómo nuestros resultados podrían ser utilizados para adquirir mejor evidencia histórica que ayude a entender las conexiones entre los tres episodios principales de violencia ocurridos en el México independiente.

\section{LOS FACTORES CONTEMPORÁNEOS DE LA VIOLENCIA CRIMINAL}

Con pocas excepciones que discutimos en la siguiente sección, la investigación sobre violencia criminal se ha centrado en el estudio de sus causas mediatas, con un énfasis en cinco factores: $a$ ) competición criminal; $b$ ) confrontación militar; $c$ ) geografía; $d$ ) competencia política, y $e$ ) oportunidad individual. $^{1}$

En primer lugar, el argumento principal que se ha desarrollado para explicar los patrones de la violencia criminal contemporánea es la transformación de grupos tradicionales orientados al trasiego de drogas en organizaciones que, además de cooptar mercados ilegales, también extraen rentas de las poblaciones a las que venden protección y distribuyen bienes a cambio de no atacarlas (Magaloni et al., 2020).

Los grupos criminales sucesores del histórico grupo de Guadalajara, con raíces en Sinaloa, Tijuana y Ciudad Juárez, se especializaron en el tráfico de drogas hacia Estados Unidos (seguimos aquí, principalmente, la cronología de los grupos criminales presentada por Valdés, 2013). Para estos grupos, la violencia era un mal necesario que hay que dosificar para evitar atraer los focos mediáticos y de la fuerza pública. Por el contrario, la aparición de los Zetas, brazo armado del cártel del Golfo, con la encomienda de disputar a otros grupos criminales del norte el control de las principales rutas de transporte de droga hacia Estados Unidos, supuso una alteración radical del mapa criminal. El cártel del Golfo permitió que los Zetas se financiaran a través de la explotación de las actividades ilícitas en los lugares por los que se desplegaban, así como de la extracción de rentas de los pobladores locales. Para ser creíbles en el negocio de la extorsión, los Zetas desplegaron un nivel de violencia tan elevado que produjo el surgimiento de otras bandas criminales como los Caballeros Templarios en Michoacán, encargados inicialmente de expulsarlos del territorio en nombre de la población local (si bien, después cayeron en las mismas prácticas predatorias).

Así, la creciente violencia ha sido explicada por la mayor competición entre grupos criminales a partir del surgimiento de los Zetas, y por el mayor énfasis de estos grupos en estrategias predatorias. Nos falta una mejor representación del fragmentado mapa criminal actual, ya que la supuesta defunción de los Zetas no ha provocado un regreso a las prácticas tradicionales de los grupos delictivos dedicados al comercio de estupefacientes, además que han surgido grupos dedicados a la explotación sistemática de materias primas como el nuevo Cartel de Santa Rosa, enfocado en el llamado huachicoleo. Parecería que el negocio de la extorsión es demasiado apetitoso para que los criminales renuncien a él.

${ }^{1}$ Para una revisión general de la literatura, véase Zepeda (2018). 
Además de la disputa entre cárteles, varios autores han destacado la intervención militar como un elemento que, lejos de apaciguar a los criminales, contribuyó a generar una creciente ola de violencia retributiva (Trejo y Ley, 2016; Atuesta y Ponce, 2017; Flores-Macías, 2018). El despliegue de los militares en funciones de vigilancia interna no ha reforzado un débil estado de derecho, pero ha desarrollado prácticas de guerra (como el descabezamiento de las organizaciones armadas) poco adecuadas para reducir el nivel de violencia criminal (Phillips, 2015). Cabe preguntarse, en cualquier caso, hasta qué punto el recurso a los militares ha provocado la violencia o si se trata de una respuesta inadecuada que simplemente ha contribuido a reforzar las dinámicas perversas de la resolución de disputas criminales.

El tercer factor corresponde a la geografía, al hecho obvio de que la ubicación de México en la frontera sur de Estados Unidos genera ganancias exorbitantes para aquellos dispuestos a asumir el riesgo de traficar con mercancías ilegales, dado el diferencial de riqueza per cápita entre los países vecinos. Esto explicaría en parte la alta concentración de la violencia criminal en los estados mexicanos del norte. Pero la geografía también abarca otros elementos, como las plantaciones de marihuana y amapola en varios estados de la República, o la existencia de puertos por los que transitan mercancías hacia Estados Unidos y Europa.

Quizá uno de los aspectos más debatidos del fenómeno criminal es su conexión con la contienda político-electoral (Hernández-Huertas, 2020). Algunos autores apuntan a un esfuerzo concertado por las autoridades políticas para utilizar el fenómeno criminal como excusa para desgastar a rivales políticos (Trejo y Ley, 2020), mientras que otros apuntan a la existencia de una descoordinación intergubernamental entre distintos niveles de gobierno (Ríos, 2013). En cualquier caso, el impacto de la competencia política debería estar concentrado en el corto plazo, por lo que para un análisis de largo plazo como es el nuestro, los efectos político-electorales seguramente juegan un papel menor.

Finalmente, varios autores han discutido el impacto de factores económicos en la difusión de la violencia criminal. Estos factores han distinguido características individuales y estructurales. Las primeras se refieren a variables microeconómicas, como la pobreza o el nivel de desigualdad (Ramírez, 2014), así como al efecto de variaciones exógenas en los mercados agrícolas sobre la producción de drogas (Dube, García-Ponce y Thom, 2016). La idea general es que determinadas condiciones económicas (más pobreza y desigualdad, mayor vulnerabilidad frente a sacudidas externas) hacen a las personas más propensas a participar en mercados ilegales, lo que alimenta el ciclo de la violencia criminal.

Los factores estructurales se refieren a la debilidad o fortaleza de las instituciones públicas, principalmente de los aparatos de seguridad, administrativo-judicial y de recaudación de impuestos (este último como condición necesaria para financiar los dos previos). Estos factores se enfocan en las restricciones a las organizaciones que utilizan métodos violentos para controlar mercados ilegales y resolver disputas. El principal factor causal del inicio de guerras civiles es la debilidad de las instituciones del Estado (Fearon y Laitin 2003), y podría serlo aún más en conflictos violentos donde las ideologías no parecen jugar un papel relevante. Sin embargo, la literatura encuentra evidencia mixta a este respecto, pues medidas clásicas de capacidad estatal, como la riqueza per cápita o la tasa de escolaridad, suelen mostrar una correlación positiva con la violencia criminal que no es del todo congruente con la predicción teórica (Osorio, 2013). Por otro lado, aproximaciones más cualitativas han enfatizado la debilidad del estado mexicano como un ingrediente 
fundamental de la penetración criminal en el país (Pansters, 2012). Nuestra contribución va más en esta línea, al sugerir rutas de debilitamiento o fortalecimiento estatal que hubieran ayudado a difundir o contener la actual violencia criminal.

\section{LOS LEGADOS DE LA VIOLENCIA POLÍTICA}

Hay una literatura creciente en el estudio de la violencia política, la cual mira más allá de los factores estructurales contemporáneos del conflicto (como la riqueza, la heterogeneidad étnica, la desigualdad, o el tipo de régimen del país) y se enfoca en la existencia de sucesos del pasado que provocaron una alteración permanente de los equilibrios internos previos del país (critical junctures), con consecuencias de largo aliento sobre los patrones actuales de la violencia. Para África, por ejemplo, varios autores han mencionado la robusta conexión entre las instituciones pre-coloniales y los distintos tipos de movimientos insurgentes de descolonización, en resultados contemporáneos diversos como la probabilidad de conflicto violento o el grado de consolidación democrática (Wig, 2016; García-Ponce y Wantchekon, 2011). Sin ánimo de ser exhaustivos, también existe una rica literatura que identifica patrones contemporáneos de comportamiento electoral, relacionados con otros conflictos similares ocurridos en el pasado. Por ejemplo, De la Calle (2015) encuentra efectos de la guerra civil española y el terrorismo de ETA sobre la solidificación de patrones de comportamiento electoral, tras el fin de la dictadura franquista en regiones con fuerte sentimiento nacionalista como Cataluña y el País Vasco. Por su parte, Wittenberg (2006) y PopEleches (2007) identifican un fuerte peso del pasado en las trayectorias observadas en los países de Europa del Este tras la caída de la Unión Soviética en 1990.

Para el caso mexicano, ¿existe alguna evidencia del impacto de conflictos violentos del pasado en resultados contemporáneos? Existen al menos cuatro trabajos al respecto. Osorio, Schubiger y Weintraub (2017) encuentran que el origen local de las autodefensas en México puede ser rastreado hasta el apoyo a los grupos cristeros durante las guerras de religión que afectaron al país en la década de 1920. Estos mismos autores encuentran que las desapariciones forzosas de militantes de izquierdas, acaecidas durante la llamada "guerra sucia" de los años setenta, también tienen un impacto sobre la capacidad estatal contemporánea de los municipios mexicanos (Osorio, Schubiger y Weintraub, 2018).

Remontándose a la revolución mexicana a principios del siglo xx, Dell (2012) investiga el efecto a nivel municipal de la violencia revolucionaria en los resultados económicos municipales de los años cincuenta. La autora señala que los municipios que sufrieron niveles más altos de violencia mostraron un peor comportamiento en términos de producción de bienes públicos y recaudación fiscal. En una línea parecida, Sánchez-Talanquer (2018) encuentra que los intentos del Estado post revolucionario por construir alianzas con grupos armados locales -a los que se encargó de combatir contra la insurgencia cristera- fueron contraproducentes, pues generaron una menor capacidad institucional local y una mayor propensión a actuar fuera de la ley en la actualidad (por ejemplo, a través de la creación de auto defensas).

Dos investigaciones matizan un poco ese efecto negativo de la violencia. Ciertamente, el final de la revolución supuso la consolidación de una nueva clase de caciques militares que debían enfrentar un poder económico agrario autónomo (Brading, 1980). Pero Garfias (2018) muestra cómo reducciones exógenas del poder económico de la clase terrateniente fueron aprovechadas por los caciques políticos para apropiarse de la tierra, incrementar la capacidad institucional en sus feudos y así garantizar una mejor conexión política con el centro. 
De forma similar, en un trabajo reciente, Arias y De la Calle (2021) encuentran que los municipios en donde las fuerzas realistas crearon milicias -sostenidas económicamente por las elites durante la guerra de independencia- presentaban una mayor capacidad local (medida por la tasa de empleados públicos por cada 1000 habitantes) a finales de siglo xix que los municipios donde no hubo conflicto; por el contrario, la capacidad fiscal de los municipios con presencia de rebeldes parece no ser distinta a la de municipios sin conflicto independentista. El argumento es que las elites no se dividieron en aquellos municipios con milicias realistas, lo que permitió ampliar la administración y mantener el control de los recursos públicos al menos hasta el surgimiento de la revolución.

Lo que proponemos en este trabajo, es investigar los efectos de largo plazo de la violencia del pasado sobre la actual oleada de violencia criminal. Nuestro argumento rastrea dos vetas. Por un lado, un argumento clásico de que la violencia tiende a retroalimentarse, de forma que en ausencia de nuevas instituciones que resuelvan las disputas que dieron origen al conflicto, las nuevas fracturas sociales (sean de raíz socioeconómica y/o política) tenderán a concentrar la violencia en los mismos lugares del pasado (Besley y Reynal-Querol, 2014). Este argumento fluye a través de dos canales: $a$ ) los lugares con más violencia suelen tener estructuras institucionales más débiles, de forma que cuando surge un nuevo conflicto, los rebeldes tienen más facilidades para operar en dichas zonas (Fearon y Laitin, 2003), y $b$ ) la violencia recurrente crea un capital humano acumulado en el arte de la guerra, una especialización que se hereda generacionalmente y que posibilita que las nuevas fracturas sean más explotadas oportunamente en lugares donde existe este capital especializado en la violencia (Fearon y Laitin, 2014).

Por otro lado, nuestro segundo argumento apunta al efecto positivo de la violencia política sobre la construcción de capacidades estatales. Siguiendo la contribución seminal de Tilly (1992) respecto al impacto de las guerras entre Estados sobre el fortalecimiento de las estructuras institucionales, retomamos el argumento de Arias y De la Calle (2021) para proponer que la guerra de independencia mexicana también ha dejado un legado positivo sobre la capacidad institucional local, pero solo en aquellos municipios en los que se crearon milicias realistas durante la guerra y que fueron capaces de evitar el impacto negativo del periodo revolucionario. Las milicias realistas, además de extraer más recursos para mantener el esfuerzo militar, fueron clave para defender a las elites locales de la amenaza insurgente y asegurar su coordinación una vez que la independencia fue finalmente declarada. Esta posición ventajosa fue desafiada por la insurgencia revolucionaria. Siguiendo a Garfias (2018), los municipios en los que la antigua elite fue capaz de evitar la ocupación de los revolucionarios -y el debilitamiento de las tradicionales estructuras de poder localdebieran mostrar una menor penetración de la violencia criminal hoy en día, como corolario de un legado de mayor capacidad local que, en parte, sirve para disuadir el desafío abierto de los grupos criminales.

En general, la literatura sobre legados acierta al rastrear los vínculos históricos entre resultados actuales y sucesos del pasado, pero sufre a la hora de explicar los mecanismos causales que conectan a ese pasado lejano con el presente (véase Wittenberg, 2015). A continuación, discutimos a detalle los mecanismos por los que la violencia del pasado podría tener una presencia duradera en la geografía de la violencia criminal. Una vez presentados, investigamos la existencia de vínculos estadísticos entre las dinámicas de la violencia histórica en México y la violencia criminal actual. 


\section{Mecanismos}

Los conflictos violentos son fenómenos que alteran profundamente el tejido social en el que se insertan. Las guerras, más concretamente, pueden tener consecuencias que van más allá de sus efectos mecánicos (como la destrucción de capital físico o la catástrofe demográfica); las guerras, además, generan dinámicas de extracción fiscal que podrían permanecer una vez establecidas, independientemente de que desaparezcan las condiciones de violencia que las crearon (Tilly, 1992; para un argumento similar aplicado a guerras civiles, véanse Slater, 2010). Este efecto de largo plazo es aún más acusado en países que transitan a través de la guerra hacia su independencia, ya que aquella contribuye a cristalizar nuevas coaliciones de poder que se perpetúan con la legitimidad y recursos ganados durante el proceso de descolonización (García-Ponce y Wantchekon, 2011).

El caso de México es especialmente relevante, porque su guerra de independencia terminó con dos características destacadas: en primer lugar, la resolución final vino de un acuerdo entre rebeldes y fuerzas militares virreinales que permitió un reparto del nuevo poder independiente; y por otro lado, tanto la guerra como la negociación posterior contribuyeron a una fuerte descentralización del gobierno que reforzó las posiciones de poder de los nuevos caciques locales. En este escenario, la convergencia entre elites económicas y elites políticas de origen militar, en los municipios en donde se formaron con éxito milicias locales realistas, favoreció la cooperación necesaria para mantener instituciones, si bien precarias, de recaudación fiscal a nivel local, a la vez que monopolizaban todos los puestos públicos.

Por el contrario, las elites supervivientes en áreas de fuerte presencia rebelde durante la guerra enfrentaron un escenario menos optimista, ya que, en estas últimas áreas, los rebeldes se acostumbraron a bloquear la recaudación fiscal del gobierno virreinal sin establecer mecanismos sistemáticos alternativos de extracción. Así, el acuerdo que dio fin a la guerra dejó un legado de conflicto entre las elites económicas locales y la nueva elite política en zonas en las que los rebeldes convertidos en jefes del ejército del nuevo país independiente ocuparon posiciones de poder político, no solo por su incapacidad (o poca voluntad política) para extraer recursos fiscales, sino también, por el permanente conflicto con las viejas elites por el control de las instituciones locales.

$\mathrm{Ni}$ las guerras de reforma ni el porfiriato hicieron mucho por alterar este equilibrio de fuerzas locales, pues la propiedad de la tierra permaneció inalterada o, en el peor de los casos, se concentró aún más en las manos de la elite terrateniente. La revolución de 1910 sí modificó profundamente esos equilibrios locales previos y, como ya mencionamos, produjo un debilitamiento generalizado de las capacidades institucionales (Brading, 1980). Así, siguiendo a Fearon y Laitin $(2003,2014)$ esperaríamos que la presencia de organizaciones criminales fuera más común en las zonas con legado revolucionario, en parte por el debilitamiento de las estructuras de poder, en parte por la herencia de capital humano especializado en el arte de la insurgencia, y en parte por la existencia de elites divididas que permitieron la explosión de clivajes domésticos por actores armados (Arjona, 2017; Banerjee e Iyer, 2008).

En contraste, esperaríamos que los municipios con presencia de milicias realistas durante la guerra de independencia muestren un menor impacto de la actual violencia criminal, que aquellos sin legado realista, principalmente por el legado de una organización local menos dividida y capaz de generar cooperación entre elites políticas y económicas. Así, sugerimos que la presencia realista durante la guerra de independencia atenúa el impacto positivo de la revolución sobre la actual 
violencia criminal, y que los niveles menores de violencia criminal hoy en día se concentran en los municipios con presencia realista durante la independencia y ausencia de insurgencia durante la revolución.

En resumen, el primer mecanismo que queremos rastrear es el legado de una administración local con mayor capacidad de coordinar una resistencia eficaz a la penetración de la criminalidad organizada, en tanto que su herencia de clivajes y conflictos entre elites es menor. En este sentido, quizá la relación positiva que la literatura encuentra entre capacidad institucional contemporánea y violencia criminal tenga que ser mediada por las diferentes experiencias de la violencia del pasado. Así, al interactuar los legados de la violencia con la capacidad institucional local, debiéramos observar que el efecto mitigador de la capacidad estatal se concentra principalmente en los municipios con un legado de presencia realista sin revolución.

Exploramos dos mecanismos adicionales en este artículo. En primer lugar, la literatura ha destacado el impacto atenuante de las instituciones indígenas sobre la violencia criminal. La discusión se ha centrado en si instituciones como usos y costumbres son suficientes para limitar la entrada de grupos criminales, o si son necesarios mecanismos de movilización que mantengan las instituciones vigilantes ante posibles amenazas externas (véase Romero y Mendoza, 2014; Ley, Mattiace y Trejo, 2019). Sin embargo, apenas se ha analizado si la conexión entre estas instituciones y la violencia tiene raíces más profundas en el tiempo a través de los pueblos de indios, entidades corporativas del virreinato reconocidas legalmente y con al menos 80 tributarios, con iglesia, gobernantes indígenas y dotación de tierra inajenable, según la definición de finales del siglo xviII (Tanck, 1999). De hecho, el porcentaje de población indígena en el municipio es un factor que, de acuerdo con nuestros datos, correlaciona negativa y significativamente tanto con el desarrollo de la guerra de independencia, como con el surgimiento de insurgencias durante la revolución. Si las comunidades indígenas fueron capaces de evitar los principales conflictos violentos del país, no debería sorprendernos que hayan sido capaces de evitar la explosión de violencia criminal. Así, y en concordancia con el primer mecanismo, un legado institucional de los pueblos de indios puede facilitar la coordinación colectiva para resistir la penetración de la criminalidad, amortiguando el posible efecto negativo de la revolución incluso en municipios con ausencia de legado de milicias realistas.

El último mecanismo que investigamos en este trabajo es el efecto del reparto agrario sobre la violencia criminal. La reforma agraria debió reducir el impacto negativo hipotético de la violencia revolucionaria sobre la violencia criminal actual, al contener las demandas de las poblaciones más agraviadas. No obstante, el uso estratégico de las reformas de la propiedad de la tierra por parte de las autoridades priistas para garantizar la lealtad al régimen revolucionario pudo también haber ocasionado una debilidad institucional auto impuesta, así como conflictos locales (SánchezTalanquer, 2018; Saffon, 2014; Sanderson, 2013) que no ayudaría hoy a enfrentar la amenaza criminal. Asimismo, la reforma agraria otorgó derechos de propiedad incompletos que pudieran explicar el retraso económico actual de zonas con alta concentración de tierras ejidales (De Janvry, Gonzalez-Navarro y Sadoulet, 2014; Albertus et al., 2016).

En resumen, nuestros tres mecanismos apuntan a rutas a través de las cuales la violencia del pasado tendría un efecto en la violencia actual. En primer lugar, las comunidades indígenas han mostrado una alta coordinación a la hora de evitar la violencia. Segundo, las elites terratenientes - asociadas a las milicias realistas que garantizaron su posición de poder tras la independencia y evitaron la insurgencia revolucionaria- construyeron capacidades institucionales más robustas que ayudarían ahora a evitar la expansión criminal. Y finalmente, los municipios que fueron sacudidos 
por la revolución tendrían más violencia criminal como consecuencia de una mayor debilidad institucional y porque los problemas de la tierra nunca quedaron resueltos del todo, dada la incierta estructura de propiedad que se impuso.

\section{DATOS}

Para contrastar empíricamente nuestras expectativas teóricas, hemos creado una base de datos que incluye como observaciones los 2456 municipios de México que existían en 2010, aunque cabe mencionar que el número de observaciones incluidas en los modelos varía en función de la disponibilidad de los datos. Nuestra variable dependiente es la suma para cada municipio de los homicidios dolosos del fuero común entre 2006 y 2011 recopilados por Maldonado y Grau (2013), y entre 2015 y 2018 de acuerdo con el conteo proporcionado por el secretariado ejecutivo del Sistema Nacional de Seguridad. ${ }^{2}$

Nuestra variable principal combina el impacto de la guerra de independencia y de la revolución. Respecto a la independencia, hemos codificado para cada municipio la presencia de milicias y rebeldes a partir del meticuloso trabajo realizado por Ortiz (2014), quien registró la presencia de grupos de insurgentes y de milicias realistas organizadas por civiles en las localidades del país. A partir de estos datos, identificamos tres tipos de municipios: $a$ ) los que tuvieron presencia insurgente; $b$ ) los que tuvieron presencia realista o fueron recapturados por los realistas (los segundos en grupos insurgentes y milicias civiles); y c) los que no sufrieron la presencia permanente de los bandos en conflicto (véase Arias y De la Calle, 2021) (véase gráfica 1).

Por otro lado, Sánchez-Talanquer (2017) ha realizado la codificación más exhaustiva hasta el momento del desarrollo de actividades armadas durante el periodo armado de la revolución (1910-1917). A partir de la definición previa de Dell (2012), un municipio fue identificado con presencia insurgente "si vecinos del municipio participaron en actos armados sistemáticos contra las autoridades del municipio y las fuerzas de seguridad o para confiscar las propiedades de otros" (Sánchez-Talanquer, 2017, p. 80) (véase cuadro 1). Lamentablemente, no contamos con información detallada sobre la distribución territorial de los cuatro bandos principales en conflicto (federales, carrancistas, villistas y zapatistas), por lo que no podemos distinguir si alguno de estos grupos promovió dinámicas de extracción fiscal que sobrevivieran a la revolución. En cualquier caso, todas las narrativas de la guerra coinciden en resaltar la debilidad institucional generalizada que siguió a la revolución, así que la ausencia de datos en este sentido podría no suponer un gran problema.

Según la distribución del cruce de las dos variables de conflicto: $a$ ) la mayoría de los municipios del país ( 57 \%) no tuvieron una afectación armada permanente en ninguno de los dos conflictos; $b$ ) la revolución se concentró en un espacio relativamente limitado del país, con presencia en 34 \% de los municipios, y aun menor fue la cobertura geográfica de la guerra de independencia, con $16 \%$ de municipios afectados según nuestros datos, y $c$ ) de los municipios que sí experimentaron ese conflicto, un poco menos de la mitad también tuvieron presencia revolucionaria.

${ }^{2}$ Los datos para los años 2012-2014 no siguen la misma metodología de registro y por eso no fueron incluidos en el análisis. En cualquier caso, se trata de años con un ligero retroceso de la violencia. Los datos entre 2015 y 2018 fueron descargados el 1 de julio de 2020 de la siguiente página https://www.gob.mx/sesnsp/acciones-y-programas/datosabiertos-de-incidencia-delictiva?state=published 


\section{GRÁFICA 1. MEDIA DE VÍCTIMAS DE LA VIOLENCIA GRIMINAL POR CADA 100000 HABITANTES PARA LAS CATEGORÍAS DE LOS LEGADOS DE CONFLICTO}

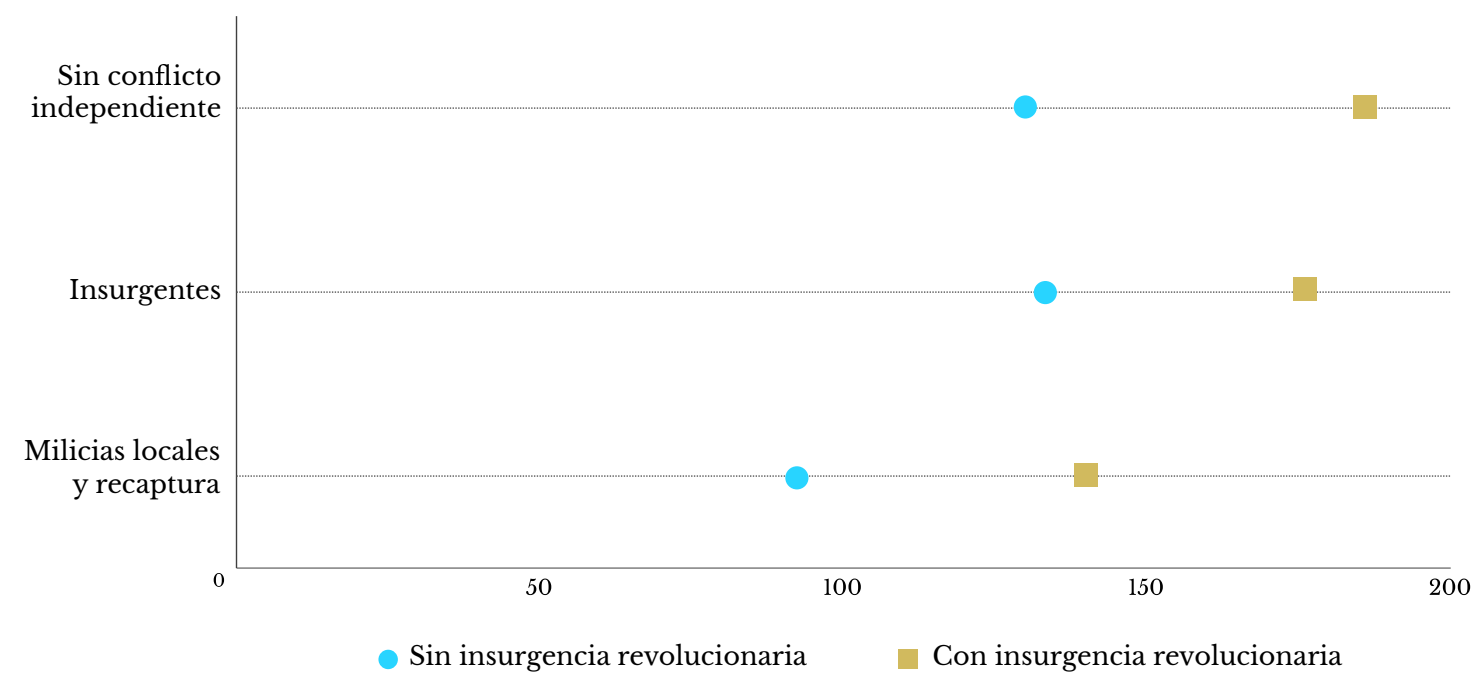

Fuentes: elaboración propia con base en Arias y De la Calle (2021) y Ortiz (2014).

En una prueba simple preliminar de la relación entre esas seis categorías de conflicto y la actual violencia criminal (véase gráfica 1), los resultados indican claramente que los municipios con experiencia revolucionaria se encuentran más afectados por la violencia criminal que los municipios que no tuvieron grupos revolucionarios locales. Por otro lado, los municipios con milicias realistas muestran un patrón de violencia criminal más benigno, especialmente cuando se trata de municipios que no sufrieron la violencia revolucionaria.

A partir de nuestro argumento teórico y de los resultados recién mostrados, reagrupamos las seis categorías en cuatro de la siguiente forma: $a$ ) aquellos municipios que tuvieron milicias realistas durante la guerra de independencia y evitaron el surgimiento de grupos rebeldes durante la revolución, pues ambos hechos podrían estar conectados con una mayor capacidad institucional local que tendría consecuencias sobre la violencia criminal actual; $b$ ) municipios sin milicias realistas (es decir, con solo grupos insurgentes o ausencia de violencia durante la independencia), pero con presencia revolucionaria, los cuales deberían mostrar más afectación criminal, pues las demandas rebeldes quedaron hasta cierto punto irresueltas por las reformas de la tierra y la extensión de una cultura armada no contribuyó al robustecimiento de las instituciones locales; $c$ ) municipios con realistas durante la independencia y rebeldes durante la revolución que podrían tener características distintas a las dos categorías previas, y mostrar un resultado intermedio de violencia criminal, debido al mantenimiento de algunas estructuras locales de control, pero debilitadas por la movilización revolucionaria, $\mathrm{y} d$ ) municipios que no tuvieron milicias realistas durante la independencia ni grupos rebeldes durante la revolución.

Si retomamos el mismo ejercicio simple que planteamos en la gráfica 1, pero ahora para las cuatro nuevas categorías, obtenemos que los municipios con revolución-sin milicias realistas tuvieron en promedio 181 homicidios por cada 100000 habitantes. El legado de milicias realistas en municipios con revolución reduce la violencia criminal a 134 muertes en promedio. En un agudo 


\section{GUADRO 1. DISTRIBUCIÓN DE LA PRESENGIA DE REBELDES Y MILICIAS DURANTE LA GUERRA DE INDEPENDENCIA Y LA REVOLUCIÓN}

\begin{tabular}{lrr}
\hline & \multicolumn{2}{c}{ Revolución } \\
Municipios & Sin insurgencia & Con insurgencia \\
\hline Sin violencia & $1300(57.4)$ & $597(26.4)$ \\
Con insurgentes & $80(3.5)$ & $91(4.0)$ \\
Con milicias realistas & $117(5.2)$ & $81(3.6)$ \\
\hline
\end{tabular}

Fuentes: elaboración propia con base en Arias y De la Calle (2021) y Sánchez-Talanquer (2017, p. 80).

contraste, el promedio para los municipios con milicias realistas-sin revolución baja a 98 homicidios por cada 100000 habitantes. Los municipios sin legado de presencia realista y sin violencia revolucionaria tuvieron 127 asesinatos en promedio. Estos números en general cuadran bien con nuestro argumento, pues muestran que los municipios con insurgencia revolucionaria sufren más violencia criminal que los que no la tuvieron y, además, que los municipios con realistas lograron atenuar la violencia criminal, independientemente de si experimentaron revolución o no.

Por supuesto, para comprobar si estos resultados preliminares son robustos, necesitamos tener en cuenta factores tanto contemporáneos como históricos que podrían tener un impacto sobre la actual violencia criminal. La hipótesis alternativa quizá más poderosa es una visión puramente economicista del fenómeno criminal: los grupos criminales apuntan hacia los territorios que favorecen la maximización de la extorsión independientemente de la fortaleza de los gobiernos locales y su capacidad organizativa. El papel que juega la historia sería, entonces, secundario y se reduciría a la coincidencia inter-temporal de compartir una determinada ubicación geográfica.

Para controlar por ese argumento alternativo, incluimos varias medidas geográficas en nuestra base de datos. Es indudable que la cercanía de México a la frontera con Estados Unidos -el mayor mercado de estupefacientes en el mundo- es uno de los factores que ayudan a explicar la violencia criminal en el país. También, la frontera sur está afectada por las típicas economías ilegales que prosperan en las zonas limítrofes entre países. Por eso, incluimos una variable dicotómica que identifica a los municipios mexicanos fronterizos. Además, identificamos con otra variable dicotómica a los municipios mexicanos con puertos, pues estos suelen ser un botín apreciado por los grupos criminales (no solo como lugar de tránsito de mercancías ilegales, sino como mercados atractivos para la extracción de rentas). Finalmente, incluimos un indicador de la pendiente geográfica o gradiente (promedio) del municipio, calculada con datos geográficos del INEGi como medida de productividad agrícola. En zonas con mayor gradiente es más difícil trabajar la tierra.

La información descriptiva para nuestras variables por categoría de legado de violencia política (véase cuadro 2), muestra que los municipios con presencia realista no están cerca de una frontera, mientras que hay puertos en todas las categorías, aunque con una proporción mayor en municipios sin legado realista y sin revolución. Los promedios de pendiente del terreno son similares entre categorías.

Otra historia alternativa muy común es el impacto de los factores socioeconómicos contemporáneos. Desde el punto de vista de la oferta criminal, suele mencionarse la desigualdad económica como uno de los factores que ayudan a entender el crecimiento de la violencia. Las zonas con más desigualdad generan más individuos 'perdedores' en la competencia económica, y en con- 
CUADRO 2. ESTADÍSTICA DESCRIPTIVA, EN FUNGIÓN DE LAS CATEGORÍAS DE LEGADO DE LA VIOLENCIA

\begin{tabular}{lrrrr}
\hline & $(1)$ & $(2)$ & $(3)$ & \multicolumn{1}{c}{$(4)$} \\
& $\begin{array}{c}\text { Sin realistas- } \\
\text { sin revolución }\end{array}$ & $\begin{array}{c}\text { Con realistas- } \\
\text { sin revolución }\end{array}$ & $\begin{array}{c}\text { Sin realistas- } \\
\text { con revolución }\end{array}$ & $\begin{array}{c}\text { Con realistas- } \\
\text { con revolución }\end{array}$ \\
\hline PIB per cápita (Ln) & 7200 & 7336 & 7198 & 7538 \\
& $(0.553)$ & $(0.591)$ & $(0.541)$ & $(0.424)$ \\
Población (Ln) & 9110 & 10.31 & 9367 & 10.71 \\
& $(1394)$ & $(1570)$ & $(1669)$ & $(1495)$ \\
Frontera & 0.0444 & 0 & 0.0445 & 0 \\
Puerto & $(0.206)$ & $(0)$ & $(0.206)$ & $(0)$ \\
& 0.0529 & 0.0263 & 0.0274 & 0.0341 \\
Gradiente del terreno & $(0.224)$ & $(0.161)$ & $(0.163)$ & $(0.183)$ \\
Transferencias federales & 4838 & 4482 & 4839 & 4301 \\
(porcentaje) & $(3645)$ & $(2881)$ & $(3450)$ & $(2498)$ \\
GINI & 0.308 & 0.217 & 0.279 & 0.178 \\
& $(0.268)$ & $(0.191)$ & $(0.258)$ & $(0.199)$ \\
Intensidad migratoria & 0.400 & 0.425 & 0.401 & 0.449 \\
Pueblos de indios & $(0.0539)$ & $(0.0545)$ & $(0.0594)$ & $(0.0557)$ \\
Empleados públicos locales & -0.0226 & 0.0369 & 0.0719 & 0.214 \\
Alfabetos en 1900 & $(1008)$ & $(0.959)$ & $(1036)$ & $(0.985)$ \\
Tierra repartida 1916-1946 & 0.802 & 0.855 & 0.738 & 0.830 \\
(porcentaje) & $(0.399)$ & $(0.354)$ & $(0.440)$ & $(0.378)$ \\
Observaciones & 0.93 & 1.37 & 2.29 & 1.23 \\
& $(1778)$ & $(2281)$ & $(2499)$ & $(1494)$ \\
& 0.112 & 0.130 & 0.116 & 0.189 \\
Non & $(0.0850)$ & $(0.0814)$ & $(0.0899)$ & $(0.297)$ \\
& 32.01 & 33.69 & 28.86 & 38.79 \\
& $(113.3)$ & $(27.85)$ & $(31.25)$ & $(26.58)$ \\
& 1172 & 76 & 584 & 88 \\
\hline
\end{tabular}

Nota: el cuadro muestra medias por categoría con la desviación estándar entre paréntesis.

Fuentes: elaboración propia con base en Arias y De la Calle (2021) y Sánchez-Talanquer (2017).

secuencia, una mayor oferta de mano de obra para actividades ilegales como el tráfico de drogas o la extracción local de rentas, lo que redunda en una mayor competición armada por controlar esos mercados. La brecha existente entre las recompensas ofrecidas por las organizaciones criminales y los sueldos ofertados en los mercados formales e informales permite la existencia de un amplio 'ejército de reserva' de la criminalidad, amplificado por las crecientes restricciones migratorias impuestas por Estados Unidos a partir de los ataques terroristas del 11 de septiembre de 2001 (Alonso, 2017). Así, controlamos por el coeficiente de GINI del municipio en 2005 y el índice de intensidad migratoria en 2010, ambos recopilados por el Programa de Naciones Unidas 
para el Desarrollo (PNUD). Mientras que el índice de GINI no es estadísticamente distinto por legado de violencia, en promedio, el índice de migración sí muestra diferencias para los municipios con distintos legados de violencia (véase cuadro 2 ).

Como vimos en la revisión de la literatura, la extracción de rentas es parte fundamental de las peleas entre grupos criminales. Así, quizá la violencia criminal es motivada por el tamaño del botín, más que por la ubicación geográfica o por la debilidad del estado. Para capturar esta idea, incluimos el ingreso per cápita anual en dólares del municipio en 2005, medido por el PNUD (transformamos la variable logarítmicamente para evitar su distribución sesgada). También, utilizamos las transferencias federales a los municipios como una forma de medir las oportunidades de extracción de recursos para los grupos criminales. Nuestro indicador es el ingreso por aportaciones federales y estatales a cada municipio, ponderado como porcentaje del ingreso per cápita municipal. Para evitar fluctuaciones anuales, usamos el valor promedio durante el sexenio del expresidente Felipe Calderón. Los datos de aportaciones fueron recopilados por el INEGi. Como la variable dependiente está en números absolutos, incluimos como control el logaritmo de la población total del municipio en 2010 del INEGI. Cabe resaltar que las transferencias federales sí muestran diferencias al separar a los municipios en categorías, con aquellos sin legado realista ni revolucionario recibiendo en promedio más que los demás (véase cuadro 2 ).

Quizá la parte más interesante de nuestro trabajo es intentar desentrañar las posibles conexiones de la violencia del pasado sobre la violencia criminal actual, a pesar de que en términos de motivaciones y participantes parecerían estar bastante alejadas. En la sección previa, sugerimos tres mecanismos y ahora describimos qué indicadores usaremos para operacionalizarlos. En primer lugar, la presencia de comunidades indígenas parece tener un efecto amortiguador sobre la violencia que va más allá de la actual presencia criminal. Así, utilizamos la existencia de al menos un Pueblo de Indios en el municipio, en 1800, para medir dicho efecto. Los datos se refieren al listado de pueblos de indios recopilado por Tanck (2005). En 1803 había 4081 pueblos en Nueva España.

En segundo lugar, la literatura muestra un efecto positivo de los municipios con milicias realistas en la capacidad institucional local a finales del siglo XIX, a la vez que un efecto opuesto de esa capacidad sobre la violencia criminal actual (más capacidad, más violencia). Para revelar si el efecto de la capacidad estatal es distinto en otros tipos de municipios, incluimos dos indicadores de capacidad. El primero está relacionado con la capacidad infraestructural (Soifer, 2012) y es el número de empleados públicos por cada 1000 habitantes en el municipio en 1900 (datos censales del INEGI). El segundo apunta a los resultados de la capacidad institucional y mide el porcentaje de personas alfabetizadas en el municipio en 1900 (datos censales del INEGI). La educación a finales del siglo xIX era un servicio suministrado locamente, por lo que mejores resultados podrían indicar una mayor capacidad institucional.

Finalmente, queremos observar si la correlación positiva entre la Revolución y la violencia criminal actual está mediada por la reforma agraria. Para ello, incluimos un indicador del porcentaje de tierra distribuida en el municipio entre 1916 y 1946. Los datos fueron recopilados por Sánchez-Talanquer (2017, p. 145) a partir de los datos oficiales compilados en el Registro Agrario Nacional. 


\section{Resultados}

Como la variable dependiente de interés cuenta con sobredispersión en su distribución y abundancia de ceros, empleamos estimaciones binomiales negativas con errores robustos. Reportamos las razones de probabilidades (incidence rate ratios) de que ocurra el evento de interés cuando cambia la variable independiente. Valores superiores a 1 indican un impacto positivo de la variable independiente, mientras que los valores inferiores a 1 indican lo opuesto (impacto negativo). Los valores alrededores de 1 indican un efecto nulo o insignificante (véase cuadro 3 ).

En los cuatro modelos anteriores (véase cuadro 3), los dos primeros incluyen todos los municipios del país, mientras que los dos últimos excluyen de la muestra a los estados del sur (Oaxaca, Campeche, Chiapas, Quintana Roo, Tabasco y Yucatán), pues estos muestran, en general, un impacto mucho menor de la violencia criminal. Además, los modelos 1 y 3 incluyen únicamente las variables geográficas, mientras que 2 y 4 añaden también las variables económicas. Por recordar, nuestras cuatro categorías clave de legado de la violencia son: $a$ ) municipios sin milicias realistas durante la guerra de independencia y sin presencia insurgente durante la revolución (esta es la categoría base en los modelos); $b$ ) municipios con realistas, pero sin revolucionarios; $c$ ) municipios que tuvieron presencia insurgente durante la revolución pero no milicias realistas durante la independencia, y $d$ ) municipios con presencia revolucionaria y con milicias realistas.

Independientemente de la modelización usada, observamos que los municipios con revoluciónsin realistas sufren más violencia criminal, y que los municipios sin revolución-con milicias experimentan menos violencia criminal (en ambos casos, en comparación con los municipios sin milicias-sin revolución). En línea con investigaciones previas, encontramos una relación positiva entre la riqueza contemporánea municipal y la violencia criminal. El ingreso medio suele usarse como medida de capacidad estatal, aunque en este caso, es una extrapolación un tanto dudosa, ya que el coeficiente de las transferencias fiscales federales y estatales mostrado en el modelo 2 sugiere que en los municipios más ricos el ingreso fiscal local tiene una mayor dependencia de dichas transferencias. También destaca que la desigualdad parece atenuar la violencia criminal (a más desigualdad, menos violencia), aunque ese efecto está concentrado espacialmente en el sur, una región caracterizada por el predominio de poblaciones indígenas.

Como puede apreciarse, la revolución muestra uno de los impactos positivos más poderosos, mientras que, entre los factores atenuantes, lo contrario es el caso para las milicias realistas-sin revolución (véase gráfica 2 ).

Para rastrear en profundidad a qué se deben estos efectos, incorporamos las tres variables que podrían ayudarnos a entender mejor los efectos de la violencia del pasado: pueblos de indios, capacidad institucional local a finales del siglo XIX (funcionarios públicos y tasas de alfabetización) y extensión de la Reforma agraria (véase cuadro 4). Los modelos 1 al 4 añaden cada variable de forma secuencial, mientras que los dos últimos modelos las incorporan todas. De nuevo, el modelo 6 excluye observaciones de los estados del sur.

Todos estos indicadores son estadísticamente significativos y coherentes con los hallazgos habituales de la literatura y con las medidas de capacidad institucional que incrementan la violencia, mientras que la existencia de pueblos de indios y la extensión del reparto agrario la reducen. Por otro lado, apenas alteran los efectos principales de las variables de legado. Los modelos con todas las variables muestran una relación fuerte entre la tasa de alfabetización en 1900 y la violencia criminal. Si limitamos el análisis a los estados no sureños, la variable de pueblos de indios deja de 
CUADRO 3. MODELOS DE REGRESIÓN DE VIOLENCIA CRIMINAL,
CON LEGADOS DE VIOLENGIA Y CONTROLES CONTEMPORÁNEOS

\begin{tabular}{|c|c|c|c|c|}
\hline & (1) & (2) & (3) & (4) \\
\hline Con realistas-sin revolución & $\begin{array}{r}0.746^{* * *} \\
(0.072)\end{array}$ & $\begin{array}{l}0.802^{*} \\
(0.096)\end{array}$ & $\begin{array}{r}0.722^{* * *} \\
(0.075)\end{array}$ & $\begin{array}{l}0.751^{* *} \\
(0.087)\end{array}$ \\
\hline Con revolución-sin realistas & $\begin{array}{r}1403^{* * *} \\
(0.078)\end{array}$ & $\begin{array}{r}1434^{* * *} \\
(0.080)\end{array}$ & $\begin{array}{r}1403^{* * *} \\
(0.085)\end{array}$ & $\begin{array}{r}1419^{* * *} \\
(0.085)\end{array}$ \\
\hline Con revolución-con realistas & $\begin{array}{r}0.991 \\
(0.095)\end{array}$ & $\begin{array}{r}0.953 \\
(0.083)\end{array}$ & $\begin{array}{r}0.961 \\
(0.092)\end{array}$ & $\begin{array}{r}0.954 \\
(0.088)\end{array}$ \\
\hline Población (ln) & $\begin{array}{l}2911^{* * *} \\
(0.061)\end{array}$ & $\begin{array}{l}2934^{* * *} \\
(0.080)\end{array}$ & $\begin{array}{r}2617^{* * *} \\
(0.064)\end{array}$ & $\begin{array}{r}2635^{* * *} \\
(0.082)\end{array}$ \\
\hline Frontera & $\begin{array}{r}1728^{* * *} \\
(0.349)\end{array}$ & $\begin{array}{l}1372^{*} \\
(0.241)\end{array}$ & $\begin{array}{r}2969^{* * *} \\
(0.528)\end{array}$ & $\begin{array}{r}2478^{* * *} \\
(0.441)\end{array}$ \\
\hline Puerto & $\begin{array}{r}0.900 \\
(0.107)\end{array}$ & $\begin{array}{r}0.936 \\
(0.102)\end{array}$ & $\begin{array}{r}1245 \\
(0.178)\end{array}$ & $\begin{array}{r}1176 \\
(0.170)\end{array}$ \\
\hline Gradiente del terreno & $\begin{array}{r}1006 \\
(0.009)\end{array}$ & $\begin{array}{c}1053^{* * *} \\
(0.009)\end{array}$ & $\begin{array}{r}1009 \\
(0.011)\end{array}$ & $\begin{array}{c}1033^{* * *} \\
(0.011)\end{array}$ \\
\hline PIB per cápita (ln) & & $\begin{array}{r}1815^{* * *} \\
(0.125)\end{array}$ & & $\begin{array}{r}1436^{* * *} \\
(0.116)\end{array}$ \\
\hline $\begin{array}{l}\text { Transferencias federales } \\
\text { (porcentaje) }\end{array}$ & & $\begin{array}{l}1454^{* *} \\
(0.233)\end{array}$ & & $\begin{array}{l}1413^{*} \\
(0.281)\end{array}$ \\
\hline GINI & & $\begin{array}{c}0.129^{* * *} \\
(0.073)\end{array}$ & & $\begin{array}{r}0.774 \\
(0.448)\end{array}$ \\
\hline Intensidad migratoria & & $\begin{array}{l}1054^{* *} \\
(0.028)\end{array}$ & & $\begin{array}{l}0.941^{* *} \\
(0.028)\end{array}$ \\
\hline Alpha & $\begin{array}{l}0.823^{* * *} \\
(0.034)\end{array}$ & $\begin{array}{r}0.758^{* * *} \\
(0.031)\end{array}$ & $\begin{array}{r}0.689^{* * *} \\
(0.030)\end{array}$ & $\begin{array}{r}0.664^{* * *} \\
(0.027)\end{array}$ \\
\hline Media var. dep. & 71.79 & 72.38 & 102.45 & 103.53 \\
\hline Municipios & 2261 & 2236 & 1456 & 1438 \\
\hline Wald $C h i^{2}$ & 4157.46 & 5489.43 & 2133.08 & 3450.72 \\
\hline Pseudo $\mathrm{R}^{2}$ & 0.169 & 0.178 & 0.152 & 0.156 \\
\hline
\end{tabular}

Nota: Regresión Binomial Negativa con errores estándar robustos; (3) y (4) no incluyen los estados del sur: Oaxaca, Campeche, Chiapas, Quintana Roo, Tabasco, Yucatán. Coeficientes exponenciados (incidence rate ratios): valores menores a 1 indican una relación negativa, valores mayores a 1 una relación positiva. * significativo al $10 \%$; ** significativo al $5 \%$; *** significativo al 1 por ciento.

ser significativa y el efecto de la tasa de alfabetización se modera, lo que apunta a que gran parte de su impacto está mediado por la débil penetración de las instituciones educativas en el sur antes de la revolución (véase cuadro 5). 


\section{GRÁFICA 2. EFECTOS MARGINALES DE LA VIOLENCIA POLÍTICA HISTÓRICA EN LA VIOLENCIA CRIMINAL, CON CONTROLES CONTEMPORÁNEOS}

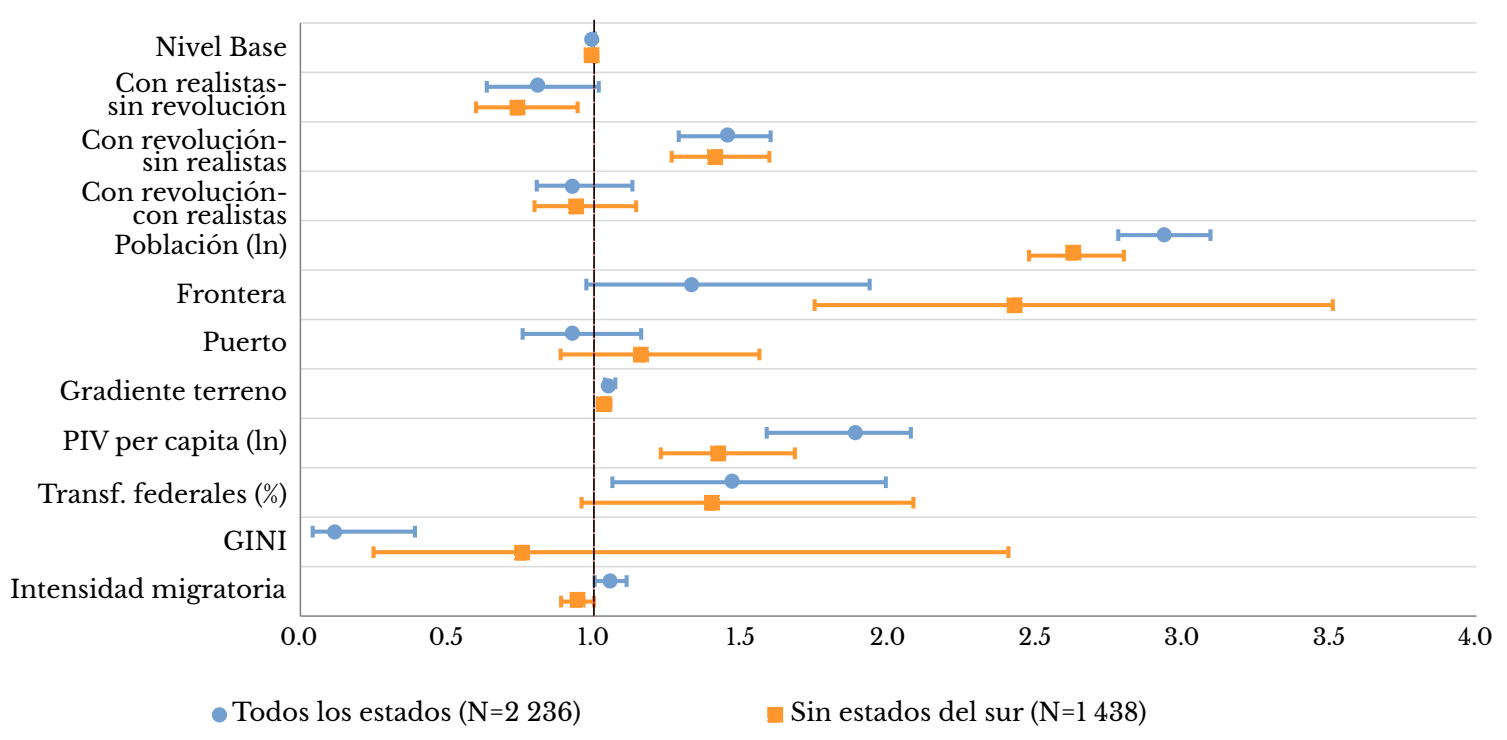

En la exposición de los mecanismos, discutimos si los efectos de las comunidades indígenas, la capacidad institucional local y la reforma agraria podrían ser mediados por el distinto legado de violencia que cada municipio experimentó (véase cuadro 5). Los dos primeros modelos muestran que la existencia de pueblos de indios a principios del siglo xIX garantiza menos homicidios criminales en la actualidad, pero que en los municipios con revolución-sin realistas la presencia de indígenas incrementa la violencia criminal. Ese efecto interactivo resiste incluso si excluimos de la muestra a los estados del sur (modelo 2). Los valores predichos de violencia criminal que incorporan el efecto total de los pueblos de indios para cada categoría de legado, resaltan el efecto atenuante de la organización indígena sobra la violencia criminal, sobre todo en municipios sin legado realista (véase gráfica 3 ).

Los modelos 3 y 4 (véase cuadro 5) muestran un efecto relativamente similar del reparto de la tierra a través de los legados de la violencia, con efectos no significativos estadísticamente o significativos pero moderados. Quizá, lo más interesante es que la reforma de la tierra parece incrementar la violencia actual en municipios que experimentaron tanto la presencia de realistas, como la revolución de 1910. El efecto total del reparto de tierras en los valores predichos de la violencia criminal, según el legado de violencia política, muestra claramente esta dinámica en los municipios con revolución (véase gráfica 4). Podemos deducir que, en los municipios con elites locales fuertes que enfrentaron insurgencias revolucionarias, la reforma agraria no contribuyó a resolver los problemas de la tierra y dejó muchas fracturas internas que siguen siendo explotadas durante el actual periodo de violencia. 


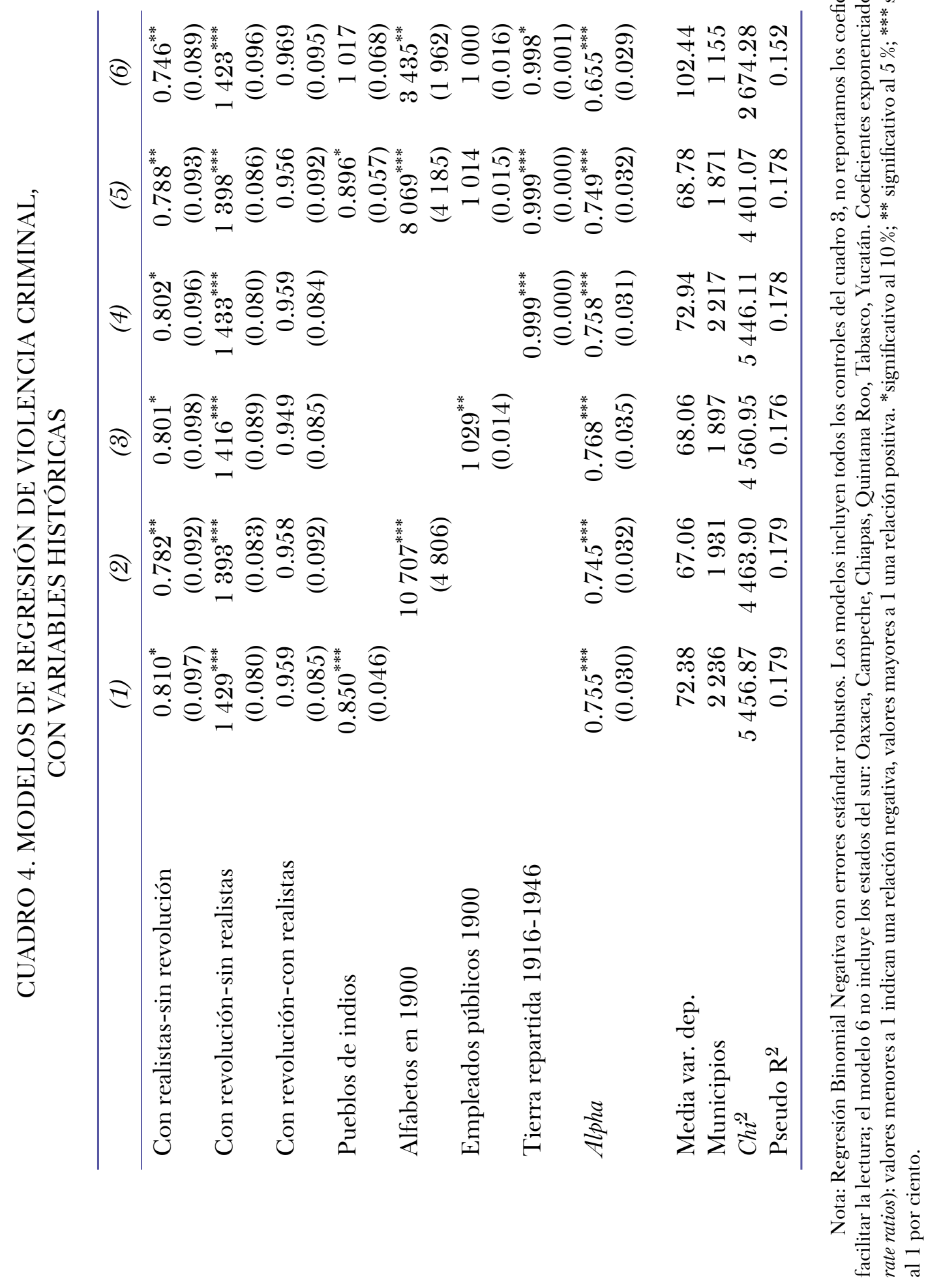




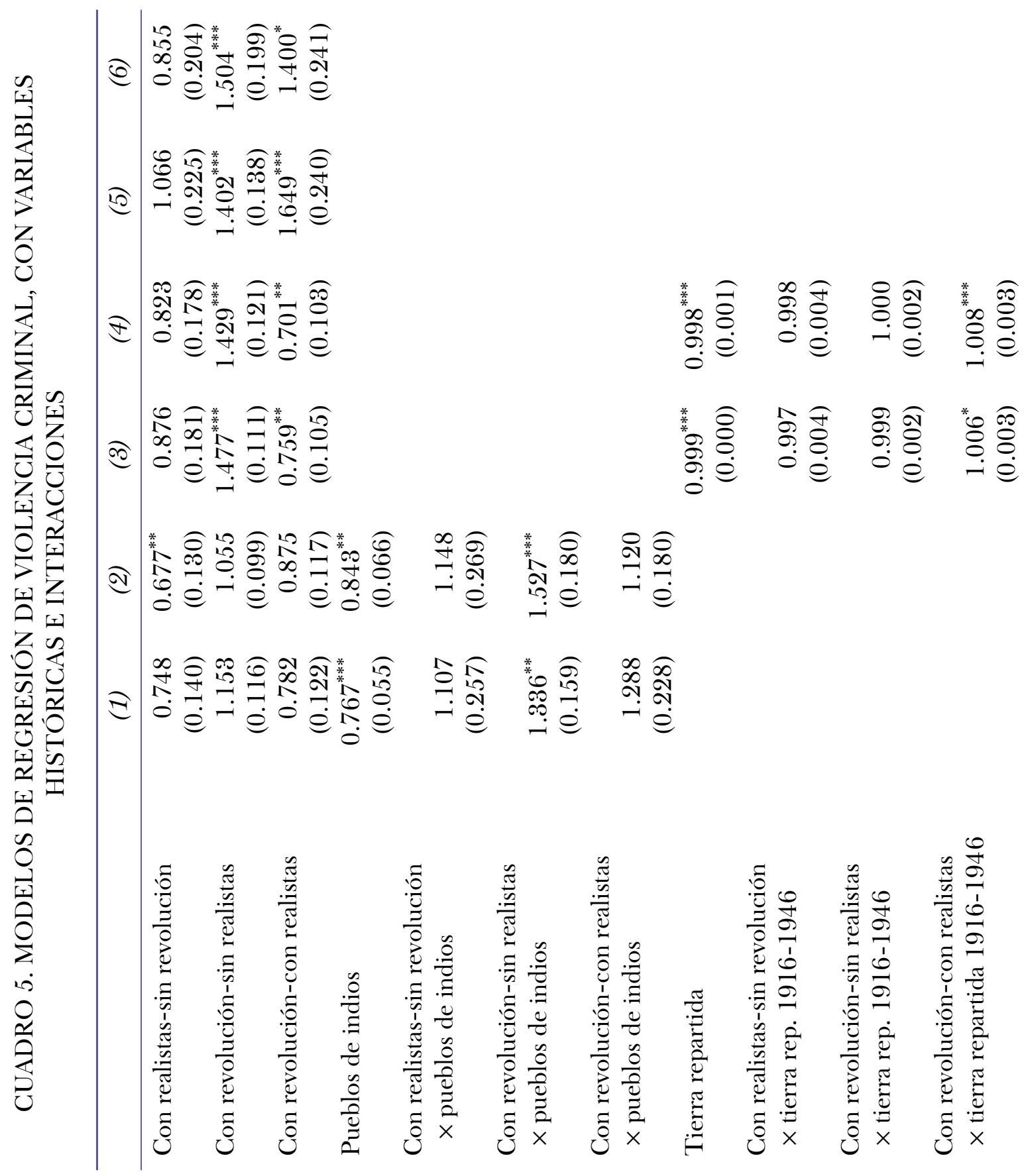




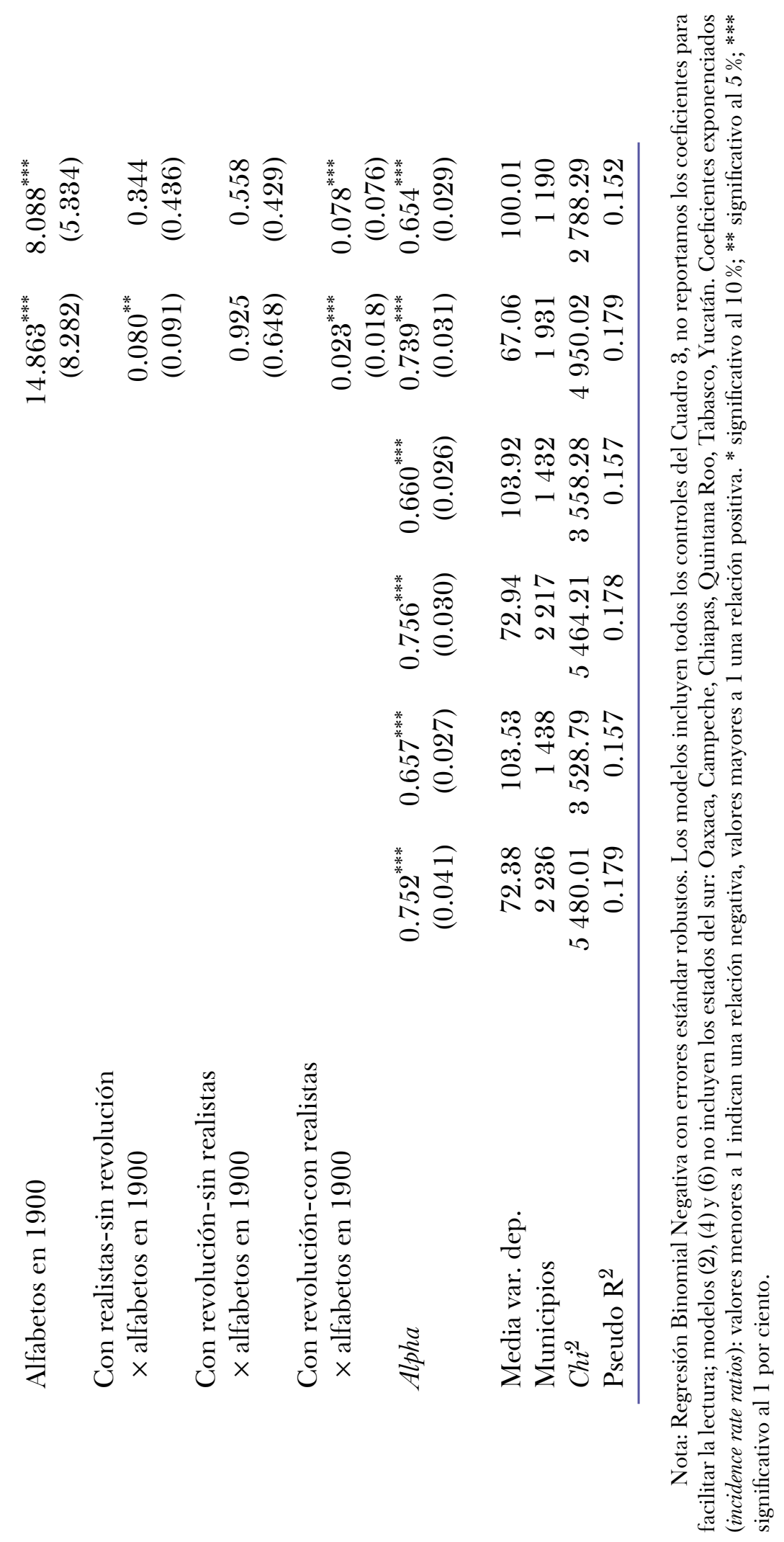




\section{GRÁFICA 3. VALORES PREDICHOS DE LA VIOLENCIA CRIMINAL Y LEGADO DE PUEBLOS DE INDIOS MEDIADO POR CATEGORÍA DE VIOLENCIA POLÍTICA, CON INTERVALOS DE CONFIANZA DE $95 \%$}

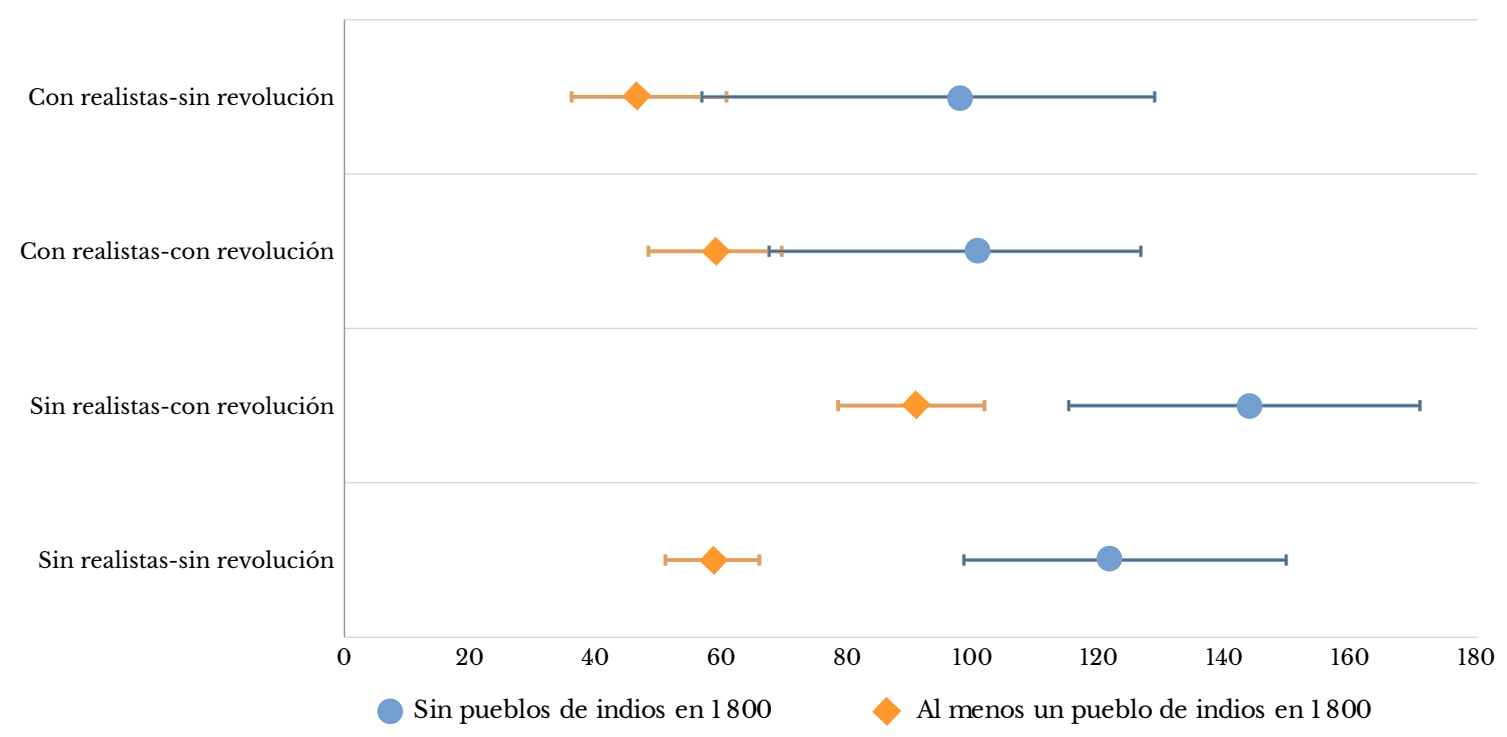

Fuente: elaboración propia con base en modelo 1 del cuadro 5.

Finalmente, los modelos 5 y 6 (véase cuadro 5) incluyen la interacción entre las cuatro categorías de violencia del pasado y la tasa de alfabetización en 1900 (las interacciones entre número de funcionarios públicos y violencia pasada no están incluidas, pues ninguna resulta significativa). Los efectos marginales (véase gráfica 5), relativos a la categoría base (municipios sin milicias-sin revolución), son mucho más destacables. A pesar de que la capacidad institucional histórica va de la mano de la violencia criminal, los municipios con un pasado realista muestran una capacidad de atenuación de la violencia actual extraordinaria, independientemente de si participaron en la revolución, sobre todo a partir de una tasa de alfabetos mayor al $20 \%$. El efecto se debilita en los municipios con realistas-sin revolución si excluimos los municipios de los Estados del sur, pues sus coeficientes son indistinguibles de los de la categoría base. En cualquier caso, estos muestran una relación positiva más débil entre alfabetismo y violencia criminal que los municipios con revolución-sin milicias realistas.

Como Arjona (2017) ha documentado para el caso de las insurgencias políticas, cuando los rebeldes se enfrentan a comunidades más organizadas, se limitan a mantener una relación superficial con la población sin inmiscuirse demasiado en la vida local. Solo en aquellos contextos donde la sociedad aparece muy desorganizada, los rebeldes intentan imponer sus instituciones y prácticas extractivas. Nuestros resultados muestran dos experiencias de este tipo: $a$ ) algunos de los municipios que contaron con milicias realistas durante la guerra fueron capaces de desarrollar una administración local más eficaz que sirvió para blindar el surgimiento de la insurgencia revolucionaria y, andando el tiempo, podría haber sido más resistente a la penetración de la criminalidad organizada, y $b$ ) la existencia de instituciones históricas de auto organización indígena ayudó a establecer filtros a la extensión de los grupos criminales y limitar su dañino potencial extractivo. 


\section{GRÁFICA 4. VALORES PREDICHOS DE LA VIOLENCIA CRIMINAL Y LEGADO DE REPARTO AGRARIO MEDIADO POR CATEGORÍA DE VIOLENCIA POLÍTICA, CON INTERVALOS DE CONFIANZA DE $95 \%$}

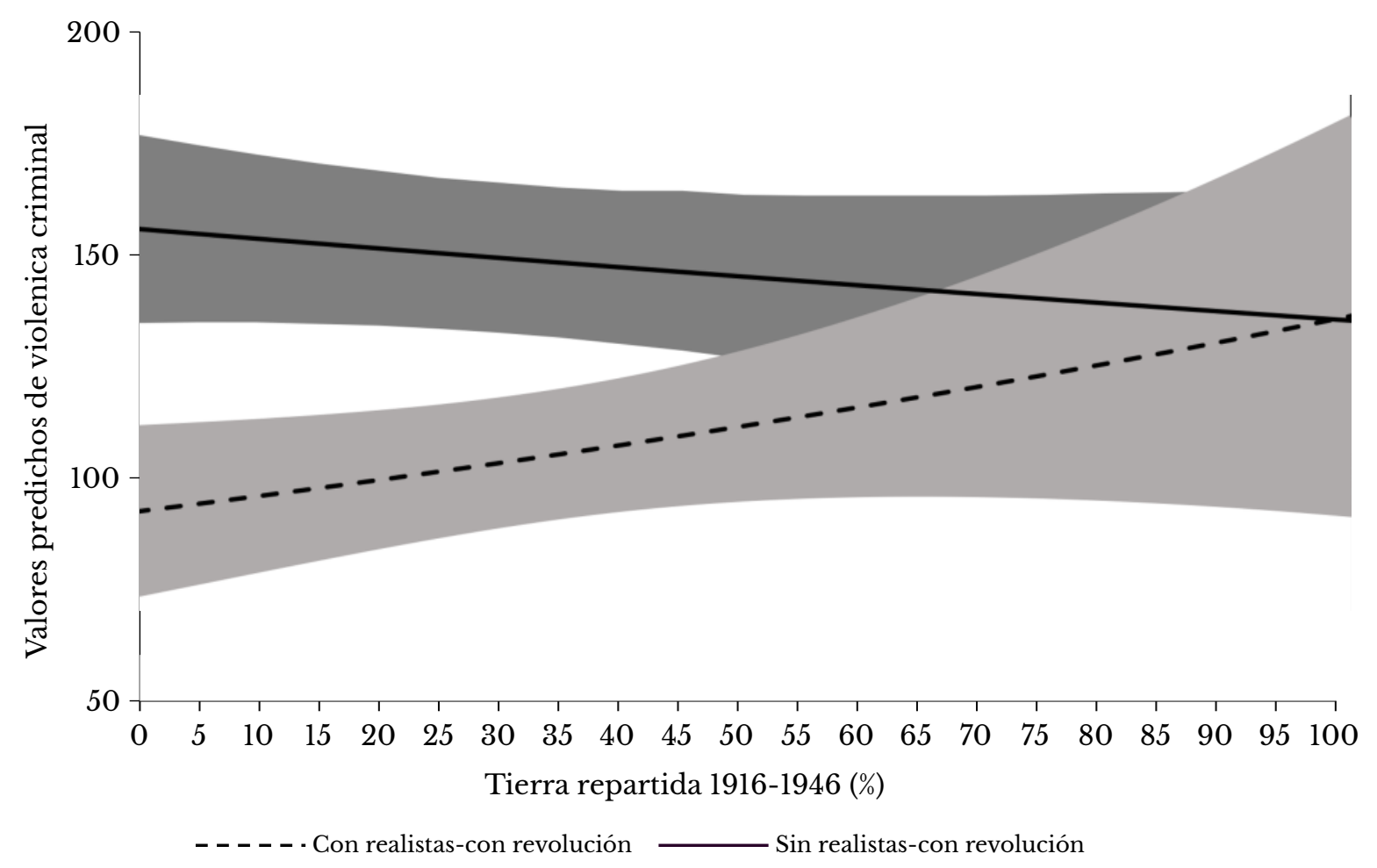

Por otro lado, en línea con estudios previos, el reparto agrario no colocó los mimbres para promover comunidades mejor organizadas frente al desarrollo de mercados que ofrecen actividades ilegales con alto rendimiento económico, pero de gran incertidumbre y riesgo en el largo plazo. En este sentido, parecería que las comunidades más afectadas por la revolución desarrollaron una especialización en la violencia como método de resolución de disputas que es aprovechada por los conflictos contemporáneos entre grupos criminales.

\section{Conclusiones}

En este trabajo, nos hemos enfocado en investigar si la actual oleada de violencia criminal tiene conexiones de largo plazo con los dos grandes episodios de violencia política que afectaron al país: la guerra de independencia y la revolución. Incluso, si controlamos por factores contemporáneos que tienen un impacto significativo sobre la variación geográfica en violencia criminal, nuestro análisis muestra una relación histórica robusta entre la violencia del pasado y la violencia actual: los municipios con presencia de milicias realistas durante la guerra de independencia y ausencia de insurgentes locales durante la revolución tienen menos violencia criminal en promedio, mientras que los municipios con insurgencia revolucionaria manifiestan una mayor afectación de la violencia criminal. 


\section{GRÁFICA 5. EFEGTOS MARGINALES DE LA PROPORCIÓN DE ALFABETOS EN 1900 EN LA VIOLENCIA GRIMINAL MEDIADOS POR CATEGORÍA DE VIOLENCIA POLÍTICA, CON INTERVALOS DE CONFIANZA DE $95 \%$}

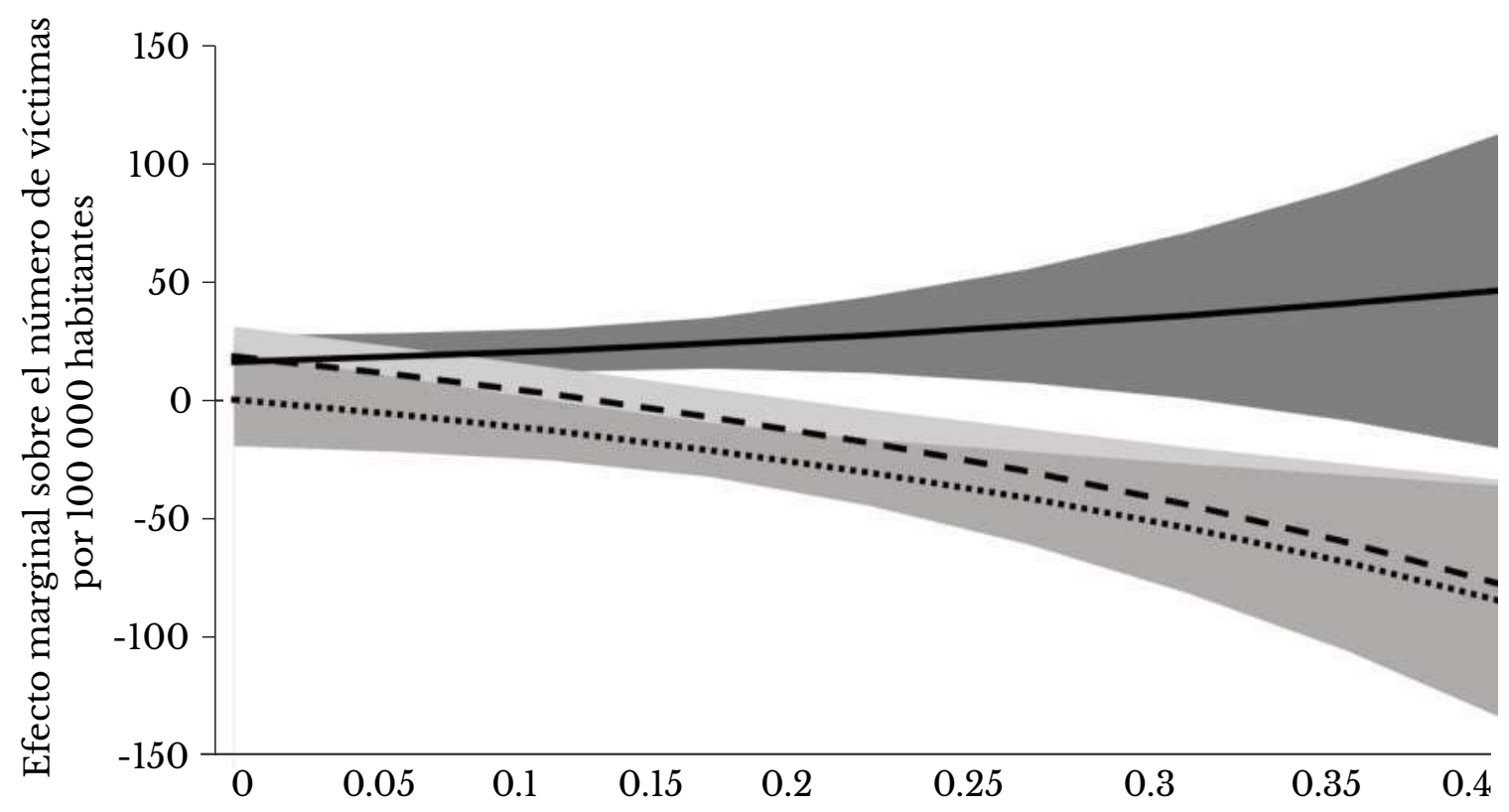

Proporción de alfabetos en 1900

Con revolución-sin realistas - - - - - Con realistas-con revolución

Con realistas-sin revolución

Para hacer sentido de estos hallazgos, rastreamos el impacto de tres instituciones de largo aliento: los pueblos de indios durante la colonia, la provisión de educación local a finales del siglo XIX y la reforma agraria post revolucionaria. Encontramos que un legado de pueblo de indios tiene un efecto atenuante sobre la violencia criminal, aunque parece concentrarse en los estados del sur de la República. Aunque hay una relación positiva entre la riqueza contemporánea de los municipios y su nivel de violencia criminal, los municipios con milicias realistas y ausencia de presencia revolucionaria muestran un impacto amortiguador de la violencia criminal gracias a una mayor capacidad institucional a finales del siglo XIx (si bien este efecto no es tan robusto). Finalmente, la reforma agraria apenas reduce el impacto positivo de la revolución sobre la violencia criminal; si acaso, para los municipios con milicias realistas y presencia revolucionaria, con reparto agrario, supone más violencia criminal, lo que apuntaría a fracturas internas de largo plazo que son explotadas por las organizaciones criminales.

Nuestros resultados apuntan al efecto demoledor que tuvo la revolución para la construcción de capacidades estatales en el país. Como Schenoni (2020) ha destacado, las guerras del siglo XIX en América Latina sí tuvieron, en parte, un efecto positivo sobre el fortalecimiento institucional, y nuestros resultados apuntan en la misma dirección. En cambio, el periodo revolucionario amplificó las debilidades del pasado y no resolvió del todo los problemas que apuntaron los levantamientos armados. Al contrario, la revolución contribuyó a alimentar una cultura de la violencia 
como resolución de disputas que podría estar conectada con la actual violencia criminal. Tenemos que seguir investigando las dinámicas regionales de la violencia durante el periodo revolucionario para comprender mejor sus conexiones con la violencia actual. Por ejemplo, necesitamos evidencia local más detallada de cómo municipios con distintos tipos de constelaciones institucionales enfrentaron la explosión revolucionaria. Además, seguimos sin contar con un mapa detallado de las dinámicas del conflicto revolucionario, las zonas de surgimiento y ocupación de los principales grupos armados, así como sus estrategias de recolección de impuestos y la distribución territorial de las distintas facciones, una vez que el conflicto llegó a su fin. Finalmente, una tercera línea de exploración son los vínculos entre la Guerra Cristera y la actual violencia criminal. Sin duda, más investigaciones nos ayudarán a tener una comprensión detallada de las conexiones profundas entre las tres principales explosiones violentas en la historia de México.

\section{LISTA DE REFERENCIAS}

Aboites, L., y Jáuregui, L. (eds.). (2005). Penuria sin fin: historia de los impuestos en México siglos XVIII-XX. Instituto de Investigaciones Dr. José María Luis Mora.

Albertus, M., Diaz-Cayeros, A., Magaloni, B. y Weingast, B. R. (2016). Authoritarian Survival and Poverty Traps: Land Reform in Mexico. World Development, 77.

Alonso, F. (2017). From the American Dream to the Mexican Nightmare. How US Border Control Enforcement and Migratory Policies Are Fueling Violence in Mexico [Doctorado]. Instituto Universitario Europeo.

Arias, L. M. y De la Calle, L. (2021). The Legacy of Civil War Dynamics on State Building: México 1810-1910. Latin American Research Review, 56(4).

Arjona, A. (2017). Rebelocracy: Social order in the Colombian civil war. Cambridge University Press.

Atuesta, L. H. y Ponce, A. F. (2017). Meet the Narco: Increased Competition Among Criminal Organisations and the Explosion of Violence in Mexico. Global Crime, 18(4). DOI: 10. $1080 / 17440572.2017 .1354520$

Banerjee, A., e Iyer, L. (2008). Historia, instituciones y rendimiento económico: el legado de los sistemas coloniales de propiedad agraria en la India. En S. Lavezzolo (ed.), Los determinantes del desarrollo económico: la causalidad en las ciencias sociales (pp. 223-277). Fundación Pablo Iglesias.

Besley, T., y Reynal-Querol, M. (2014). The Legacy of Historical Conflict: Evidence from Africa. American Political Science Review, 108(2). DOI: 10.1017/S0003055414000161

Brading, D. A. (1980). Caudillo and peasant in the Mexican Revolution. Cambridge University Press.

De Janvry, A., Gonzalez-Navarro, M., y Sadoulet, E. (2014). Are Land Reforms Granting Complete Property Rights Politically Risky? Electoral Outcomes of Mexico's Certification Program. Journal of Development Economics, 110. DOI: 10.1016/j.jdeveco.2013.04.003

De la Calle, L. (2015). Nationalist Violence in Postwar Europe. Cambridge University Press. https:// doi.org/10.1017/CBO9781139162258

De la Calle, L., y Schedler, A. (2021). ¿Borrón sin cuenta nueva? La injusticia transicional en guerras civiles económicas. Perfiles Latinoamericanos, 29(51). DOI: 10.18504/pl2957-008-2021

Dell, M. (2012). Path Dependence in Development: Evidence from the Mexican Revolution [Working Paper]. Harvard University.

Dube, O., García-Ponce, O., y Thom, K. (2016). From Maize to Haze: Agricultural Shocks and the Growth of the Mexican Drug Sector: From Maize to Haze. Journal of the European Economic Association, 14(5). DOI: 10.1111/jeea.12172 
Fearon, J. D., y Laitin, D. D. (2003). Ethnicity, Insurgency, and Civil War. American Political Science Review, 97(01). DOI: 10.1017/S0003055403000534

Fearon, L. D., y Laitin, D. D. (2014). Does Contemporary Armed Conflict Have "Deep Historical Roots"? [Working Paper]. Stanford University.

Flores-Macías, G. (2018). The Consequences of Militarizing Anti-Drug Efforts for State Capacity in Latin America: Evidence from Mexico. Comparative Politics, 51(1). DOI: 10.5129/ 001041518824414647

García-Ponce, O., y Wantchekon, L. (2011). Critical Junctures: Independence Movements and Democracy in Africa. Reunión Anual Asociación Americana de Ciencia Política, Seattle, WA.

Garfias, F. (2018). Elite Competition and State Capacity Development: Theory and Evidence from Post-Revolutionary Mexico. American Political Science Review, 112(2). DOI: 10 $.1017 / \mathrm{S} 0003055417000715$

Hernández-Huertas, V. (2020). Candidatos asesinados en México, ¿̇competencia electoral o violencia criminal? Política y Gobierno, 27(2).

Ley, S., Mattiace, S., y Trejo, G. (2019). Indigenous Resistance to Criminal Governance: Why Regional Ethnic Autonomy Institutions Protect Communities from Narco Rule in Mexico. Latin American Research Review, 54(1). DOI: 10.25222/larr.377

Magaloni, B., Robles, G., Matanock, A. M., Diaz-Cayeros, A., y Romero, V. (2020). Living in Fear: The Dynamics of Extortion in Mexico's Drug War. Comparative Political Studies, 53(7). DOI: $10.1177 / 0010414019879958$

Maldonado, G., y Grau, M. (2013). Elecciones, violencia y estructura social (EVES): base Integral de municipios mexicanos. Centro de Investigación y Docencia Económicas.

Ortiz, J. (2014). Guerra y gobierno: los pueblos y la independencia de México, 1808-1825. El Colegio de México/Instituto de Investigaciones Dr. José María Luis Mora.

Osorio, J. (2013). Hobbes on Drugs: Understanding Drug violence in Mexico [Doctorado]. Universidad de Notre Dame.

Osorio, J., Schubiger, L. I., y Weintraub, M. (2017). Vigilante Mobilization and Local Order: Evidence from Mexico. Reunión Anual de la Midwest Political Sciencie Association, Chicago, Il.

Osorio, J., Schubiger, L. I., y Weintraub, M. (2018). Disappearing dissent? Repression and State Consolidation in Mexico. Journal of Peace Research, 55(2). DOI: 10.1177/002234331 8751035

Pansters, W. G. (2012). Zones of State-Making: Violence, Coercion, and Hegemony in Twentieth Century Mexico. En W. G. Pansters (ed.), Violence, Coercion, and State-Making in TwentiethCentury Mexico: The Other Half of the Centaur (pp. 3-39). Stanford University Press.

Phillips, B. J. (2015). How Does Leadership Decapitation Affect Violence? The Case of Drug Trafficking Organizations in Mexico. The Journal of Politics, 77(2), 324-336. DOI: 10.108 $6 / 680209$

Pop-Eleches, G. (2007). Historical Legacies and Post-Communist Regime Change. The Journal of Politics, 69(4). DOI: 10.1111/j.1468-2508.2007.00598.x

Ramírez, L. D. (2014). Crimen y economía: análisis de la tasa de homicidio en México a partir de variables económicas (2000, 2005, 2010). Estudios Sociológicos, 32(96).

Ríos, V. (2013). Why Did Mexico Become so Violent? A Self-Reinforcing Violent Equilibrium Caused by Competition and Enforcement. Trends in Organized Crime, 16(2). 
Romero, V., y Mendoza, C. (2014). Is Communal Organization an Effective Deterrent to Crime? The Cases of Guatemala and Mexico. Reunión Anual de la Asociación Americana de Ciencia Política, San Francisco, CA.

Saffon, M. P. (2015). When Theft Becomes Grievance: Dispossessions as a Cause of Redistributive Land Claims in 20th Century Mexico (Tesis doctoral). Nueva York: Columbia University.

Sánchez-Talanquer, M. (2017). States Divided: History, Conflict, and State Formation in Mexico and Colombia (Tesis de doctorado). Ithaca: Cornell University.

Sánchez-Talanquer, M. (2018). Legacies of Revolution: Popular Militias and the Rule of Law. [Working paper]. México: Centro de Investigación y Docencia Económicas.

Sanderson, S. (2013). Land Reform in Mexico, 1910-1980. Ann Arbor: Interuniversity Consortium for Political and Social Research.

Schedler, A. (2015). En la niebla de la guerra: los ciudadanos ante la violencia criminal organizada. México: Centro de Investigación y Docencia Económicas.

Schenoni, L. L. (2020). Bringing War Back in: Victory and State Formation in Latin America. American Journal of Political Science. DOI: 10.1111/ajps.12552

Slater, D. (2010). Ordering Power: Contentious Politics and Leviathans in Southeast Asia. Cambridge University Press.

Soifer, H. D. (2012). Measuring State Capacity in Contemporary Latin America. Revista de Ciencia Política (Santiago), 32(3). DOI: 10.4067/S0718-090X2012000300004

Tanck, D. (1999). Pueblo de Indios y educación en el México Colonial, 1750-1821. El Colegio de México.

Tanck, D. (2005). Atlas ilustrado de los pueblos de indios: Nueva España, 1800. El Colegio de México. Tilly, C. (1992). Coercion, capital, and European states, AD 990-1992. Stanford University Press.

Trejo, G., y Ley, S. (2016). Federalismo, drogas y violencia. Por qué el conflicto partidista intergubernamental estimuló la violencia del narcotráfico en México. Política y Gobierno, 23(1).

Trejo, G., y Ley, S. (2020). Votes, Drugs, and Violence: The Political Logic of Criminal Wars in Mexico. Cambridge University Press.

Valdés, G. (2013). Historia del narcotráfico en México. México: Aguilar.

Wig, T. (2016). Peace from the Past: Pre-Colonial Political Institutions and Civil Wars in Africa. Journal of Peace Research, 53(4). DOI: 10.1177/0022343316640595

Wittenberg, J. (2006). Crucibles of Political Loyalty: Church Institutions and Electoral Continuity in Hungary. Cambridge University Press.

Wittenberg, J. (2015). Conceptualizing Historical Legacies. East European Politics and Societies: And Cultures, 29(2). DOI: 10.1177/0888325415577864

Zepeda, R. (2018). Siete tesis explicativas sobre el aumento de la violencia en México. Política y Gobierno, 25(1). 